\title{
Soy-enriched bread, a pilot study to determine its beneficial effects in
}

\section{menopause}

Daniela Giustarini ${ }^{1}$, Comasia Ricci ${ }^{2}$, Ilaria Ceccarelli ${ }^{3}$, Stefano Pieretti ${ }^{4}$, Paolo Andre ${ }^{3}$, Silvia

Migliorini $^{3}$, Lauretta Massai ${ }^{3}$, Paola Minosi $^{4}$, Ilenia Casini $^{3}$ and Anna Maria Aloisi ${ }^{3}$

${ }^{1}$ University of Siena, Department of Biotechnology, Pharmacy and Biochemistry, via Aldo Moro, 2 53100 Siena, Italy

${ }^{2}$ University of Siena, Department of Life Science, via Aldo Moro, 2 53100, Siena Italy

${ }^{3}$ University of Siena, Department of Medicine, Surgery and Neuroscience, via Aldo Moro 2, 53100 Siena Italy

${ }^{4}$ National Center for Drug Research and Evaluation, Italian National Institute of Health, Viale Regina Elena 299, 00161 Rome, Italy.

Corresponding Author: Prof. Anna Maria Aloisi. Department of Medicine, Surgery and Neuroscience, via Aldo Moro, 2, 53100 Siena, Italy; phone + 390577 232235, mobile + 39 3473579228, e-mail: annamaria.aloisi@unisi.it 


\section{Highlights}

- Women spend many years of their life with low levels of circulating estrogens

- Intake of phytoestrogens can counteract the ovary's inability to secrete estrogens

- Regular consumption of soybean in the diet can improve menopause-related symptoms

- Thirty days of soy consumption improve psychophysical and biochemical parameters 


\begin{abstract}
Menopause is the last step in the reproductive history of a woman. The ovaries stop producing hormones and the body reacts by lowering its functions, including the neuronal one. Phytoestrogens are plant products with estrogen-like activity able to affect many body functions. The aim of the present experiment was to study the effects of 30 days of regular consumption of a soy-enriched bread containing a known amount of phytoestrogens (genistein and daidzein) in climacteric or menopausal women.
\end{abstract}

Women at different stages of menopause (climacteric, within 5 years of menopause, more than 5 years of menopause) were asked to include in their diet $200 \mathrm{~g} /$ day of a bread containing $40 \mathrm{mg}$ of phytoestrogens. The effect of the regular consumption of this bread on common menopausal symptoms and neurophysiological, hormonal and antioxidant parameters were determined before and after 30 days through questionnaires and experimental tests. Phytoestrogens were measured in the urine.

In all groups, there was a significant increase of phytoestrogens in the urine and a decrease of the classical symptoms of menopause (i.e. hot flushes) as well as a significant improvement in attentional performance tests, the quality of life index and pain intensity.

Phytoestrogens are confirmed as an important supplement in aging women due to their ability to induce estrogen-like effects without the potential side effects of estrogens. Their presence in a soyenriched bread, a food commonly present in meals, avoids consideration of their consumption as a drug.

Keywords: menopause, women, phytoestrogens, bread, soy

Funding: this research did not receive any specific grant from funding agencies in the public, commercial or not-for-profit sectors 


\section{INTRODUCTION}

Menopause is a physiological condition during which women experience an abrupt change in their body aspect and functions due to the rapid decline of gonadal hormones, in particular estrogens. Until a few years ago, these hormones were considered mainly related to reproductive activity; they were not adequately considered with respect to functions such as cognition, circulation, digestion and many others not strictly related to reproduction but of crucial importance for health, particularly during aging [1]. The important involvement of gonadal hormones in these functions is confirmed by the observation that they are significantly affected by menopause [2]. For instance, after menopause the decrease of estrogens impairs cognitive functions (with loss of memory and attentional capacity), triggers the uncomfortable symptoms of hot flushes, night sweats, sleep disturbances and vaginal dryness, and increases the incidence of cardiovascular and metabolic diseases $[3,4,5]$. Most of these conditions are treated with drugs like antidepressants, without consideration of the possible hormone dependence, and subsequently the use of hormone replacement therapy (HRT) [6]. In fact, HRT was considered a possible solution [7,8,9], although the results of the Women's Health Initiative (WHI) trial indicated the possibility that long-term HRT would increase the risks of stroke and venous thromboembolism [10]. Therefore, following the publication of the WHI results the use of estrogen to treat postmenopausal symptoms has been limited. In this context, therapies based on phytoestrogens are supposed to represent a promising alternative to HRT [11]. Indeed, the important role played by phytoestrogens to mimic many of the estrogen-related functions is now widely accepted [12,13]. These molecules, present in numerous plants and structurally and functionally similar to estrogens, are known to have a great effect on many body functions [14]. Some epidemiological studies suggest that dietary intake of phytoestrogens can contribute to the decreased incidence of postmenopausal cardiovascular disease [15] and that they are significantly more effective than placebo in reducing the frequency of hot flushes [16]. A recently published meta- 
analysis in non-Asian postmenopausal women suggested that soy isoflavone supplementation could reduce body weight and improve glucose metabolism [17].

Isoflavones, lignans and coumestans are the most extensively studied phytoestrogen groups. Isoflavones are present in various edible plants, being most abundant in soy $[18,19]$. Their estrogenic activity is enhanced after metabolism to more active compounds such as genistein and daidzein by gut microbiota [20]. Once absorbed, genistein and daidzein undergo metabolic changes in the liver to be eliminated easily by the biliary tract and then reabsorbed, entering an enterohepatic cycle; significant quantities are then eliminated in the urine [21]. In people who consume soybean, blood levels of genistein and daidzein are higher than endogenous estrogens [22]. These molecules have a marked estrogenic activity, albeit 1000 times less than endogenous estrogen, and a maximum halflife of 24 hours, so daily intake is necessary to induce the positive effects and to ensure a constant level of phytoestrogens in the body [23].

Phytoestrogens bind to the estrogen receptor (ER) to carry out estrogenic and/or antiestrogenic activities [24,25], with preferential affinity for ER $\beta$ [26]. Phytoestrogens have been studied for their possible involvement in the prevention and/or treatment of a variety of pathological conditions, such as cancer, metabolic and cardiovascular diseases, neurodegeneration, inflammation and osteoporosis [26,27]. The biological activity of isoflavones on ERs seems to depend on the level of endogenous estrogens, since at high levels of endogenous estrogens the isoflavones exert antagonistic activity while at low levels they act as ER agonists [28]. Thus, in climacteric or menopausal women, their action as agonistic compounds would be beneficial. However, notwithstanding the increasing interest in their use, there is still 'resistance' to the inclusion of products containing phytoestrogens in the diet.

The aim of the present study was to test the possibility that menopausal women consuming a correct amount of phytoestrogens with bread every day would show signs of phytoestrogen-related beneficial effects. The effect on hot flushes, mood, general health, cognitive abilities and antioxidant profile are reported. 


\section{METHODS}

\section{Subjects}

Thirty healthy women recruited in the general population were asked to participate in the study. The inclusion criteria were as follows: presence of climacteric or menopausal status, no metabolic disorders, signing of the informed consent form. The exclusion criteria were: hormone replacement therapy, professionally practicing sports, undergoing body mass reduction, any special diet (including regular use of soy products). Experimental procedures were carried out in agreement with the Code of Ethics of the World Medical Association (Helsinki Declaration). All participants gave their informed consent in writing before participation.

Depending on their reproductive status, three groups were formed independently of age:

- Group 1: women with menses alteration due to the climacteric phase

- Group 2: women with absence of menses for 1 to 5 years

- Group 3: women with absence of menses for $>5$ years

\section{Experimental procedure}

The study was organized in two phases: TEST 1 (Baseline) and TEST 2 (30 days later).

During TEST 1, all subjects met a trained researcher to provide general data, to fill in questionnaires, to undergo tests and to give biological samples. After TEST 1, all participants were asked to include in their meals $200 \mathrm{~g} /$ die of soybean-enriched bread (Pariv Srl, Siena, Italy). No other dietary suggestions were given and the women had to continue their normal feeding and physical exercise habits. After 30 days, TEST 2 was carried out during which all the women were asked to repeat the measurement procedure of TEST 1.

The following experimental parameters were collected for each subject during TEST 1 and TEST 2:

Anthropometric measures and Bioelectrical Impedance Analysis (BIA)

Quality of life state by means of questionnaires:

○ Ad hoc questionnaires created to assess menopause-related symptoms: 
- Number of hot flushes per day

- Intensity of hot flushes (0-10)

- Sexual desire (0-10)

- Quality of night sleep (0-10)

○ Profile of Mood States, POMS

○ Short Form (36) Health Survey, SF-36

○ Pain questionnaires:

- Visual Analogue Scale, VAS

- Italian Pain questionnaire, QUID

Zimmerman and Fimm's Test of Attentional Performance

Urine to measure daidzein, genistein and creatinine (as normalized factor)

Saliva to measure cortisol and testosterone

Blood to measure antioxidant parameters: thiols and disulfides

- Red blood cells, RBC

o Plasma

Anthropometric measures. Weight and height measurements were carried out with an electronic medical scale and a statiometer. The values were used to calculate the Body Mass Index (BMI) using the Quetelet equation $\left(\left[\mathrm{kg} / \mathrm{m}^{2}\right]=\mathrm{P}[\mathrm{kg}] / \mathrm{A}^{2}\left[\mathrm{~m}^{2}\right]\right)$.

Bioelectrical Impedance Analysis (BIA). Bioelectrical impedance analysis (BIA) (Akern Srl, Firenze, Italy) is a commonly used method to estimate body composition. Impedance/resistance (Rz) and reactance values were analyzed with specific software (BodyGram 1.31) to obtain the following parameters: body cell mass (BCM) and body cell mass index (BCMI), total body water (TBW), extracellular water (ECW), fat mass (FM), fat free mass (FFM) [29].

Profile of Mood States (POMS). POMS, consisting of 58 items rated on a 5-point scale, measures the current psychological state of the subject [30,31]. It comprises six subscales: Tension-Anxiety (TA), Depression-Dejection (D-D), Anger-Hostility (A-H), Vigor-Activity (V-A), Fatigue-Inertia (F-I) 
and Confusion-Bewilderment (C-B). In each subscale, values higher (T-A, D-D, A-H, F-I, C-B) or lower (V-A) than 55 were considered significantly altered with respect to the normal population [32]. Short Form (36) Health Survey (SF-36). The Italian version of the SF-36 questionnaire [33] is a generic multidimensional instrument for assessing quality of life. It consists of 36 items grouped into two components and divided into eight scales: the first four scales, physical functioning (PF), role physical (RP), bodily pain (BP) and general health (GH), are included in the Physical Component Summary (PCS-36); the other four, vitality (V), social functioning (SF), role emotional (RE) and mental health $(\mathrm{MH})$, are included in the Mental Component Summary (MCS-36). Individual items are scored on a 0-100 standardized Likert scale. For each scale, a higher score indicates a better quality of life and lower limitations.

Visual Analogue Scale (VAS). VAS (0-10) was used to estimate the average pain intensity suffered during the previous week at three times of the day: morning, afternoon, night. VAS is a $10 \mathrm{~cm}$ horizontal line, anchored at the extremes by "no pain" (0) and "worst pain possible" (10) [34].

Italian Pain Questionnaire (QUID). QUID is a reconstructed Italian version of the McGill Pain Questionnaire used to determine the quality and intensity of the current pain experience [35]. It is a semantic interval scale consisting of 42 descriptors divided into four main classes: sensory, affective, evaluative, miscellaneous. All the ranks were added to obtain the Pain Rating Index Rank-Total (PRIr-T). The Present Pain Intensity (PPI) was also recorded on a 6-point scale (0-5).

Zimmerman and Fimm's Test of Attentional Performance. This test evaluates the sustained attention of the subject [36]; it is a cognitive computer test assessing several aspects of attentional control: vigilance, sustained attention, working memory and response inhibition (go/no-go). The mean reaction time ( $\mathrm{RT}=$ time in milliseconds from stimulus to response) and the number of correct responses as percentage of total responses (\% CR) during the test (accuracy) were determined to provide a combined estimate of the subject's performance. Each subject was seated in a comfortable reclining chair in front of the computer screen at a distance of about one meter, with the fingers of the dominant hand on a button on a modified computer keyboard (SuperLab Pro, Cedrus Corporation, 
USA). Figures were presented on the computer screen that could be different or the same in shape, color (red, green, blue) and size (small, medium, large); the subject had to respond by pressing the button only if the figure that appeared was equal to the previous one in form, color or size.

Analysis of genistein, daidzein and creatinine in the urine. Genistein and daidzein were determined in the first-void urine together with creatinine used to normalize values. Two hundred microliters $(0.2 \mathrm{ml})$ of urine were incubated overnight with $0.55 \mathrm{ml}$ of $0.17 \mathrm{M}$ ammonium acetate buffer pH 4.6 and $50 \mu \mathrm{l}$ glucuronidase (20000 U/ml). Samples were then extracted twice with $0.5 \mathrm{ml}$ diethyl ether and the pooled extracts were dried with a CentriVap centrifugal vacuum concentrator (Labconco), $60 \mathrm{~min}, 60{ }^{\circ} \mathrm{C}$ [37]. The resulting pellets were resuspended in $50 \mu 1$ of $80 \%(\mathrm{v} / \mathrm{v})$ methanol followed by acidification with $3.5 \mu \mathrm{l}$ of $60 \%(\mathrm{w} / \mathrm{v})$ trichloroacetic acid. Finally, samples were centrifuged at 10,000xg for 2 min and the supernatants were analyzed by HPLC.

HPLC separation was performed on a C18 column (Zorbax Eclipse XDB-C18) thermostated at $25{ }^{\circ} \mathrm{C}$. Elution was performed as follows: $0-10^{\prime}: 26 \%$ solvent B; 10'-15': $31 \%$ solvent B; $15^{\prime}-15^{\prime} 50$ '’: $100 \%$ solvent B, where solvent A was $0.25 \%$ (v/v) acetic acid pH 3.10 and solvent B was acetonitrile. A constant flow rate of $1.2 \mathrm{ml} / \mathrm{min}$ was applied. Detection was performed at $247 \mathrm{~nm}$ wavelength for daidzein and $259 \mathrm{~nm}$ for genistein. An Agilent series 1100 HPLC (Agilent Technologies, Milan, Italy) equipped with diode array and a fluorimetric detector was used for all determinations [38].

Analysis of creatinine was carried out on urine samples according to the Jaffe reaction [39]. Briefly, diluted samples (1:20) were reacted with picric acid under alkaline conditions to form a characteristic yellow-orange complex. After a 15-min incubation, the absorbance spectrum was analyzed in the wavelength range $700-350 \mathrm{~nm}$, revealing a peak at $490 \mathrm{~nm}$. In order to remove interference of nonspecific substances from the calculation, the difference in color intensity measured at $490 \mathrm{~nm}$ before and after sample acidification was considered.

Measurement of thiols and disulfides in the blood: red blood cells (RBC) and plasma. About 2 $\mathrm{ml}$ of blood were collected from the antecubital vein into tubes containing ethylenediaminetetracetic acid and $1 \mathrm{ml}$ was immediately transferred into microfuge tubes containing $100 \mu \mathrm{l}$ of $310 \mathrm{mM} \mathrm{N}$ - 
ethylmaleimide (NEM) for analyses in RBC and for disulfide analyses in plasma. After a 30-s incubation, samples were centrifuged at $10,000 \times \mathrm{xg}$ for $30 \mathrm{~s}$ and cleared of the supernatant plasma, which was stored at $-80{ }^{\circ} \mathrm{C}$. The precipitated erythrocytes were then washed by mixing with normal saline, re-centrifuged at 10,000xg for $30 \mathrm{~s}$ and separated from the supernatant saline; one aliquot of them $(0.2 \mathrm{ml})$ was deproteinized by addition of $15 \%(\mathrm{w} / \mathrm{v})$ TCA (1:1 volume). Intra-erythrocytic glutathione (GSH) and glutathione disulfide (GSSG) levels were measured in the clear supernatant. Specifically, the GSH-NEM conjugate was measured by UV/Vis HPLC [40], whereas GSSG was measured by the GSH recycling method with minor modifications [41]. The rest of the blood was centrifuged at $10,000 \mathrm{xg}$ for $30 \mathrm{~s}$ to obtain plasma. Both low molecular mass thiols (LMM-SH) and protein thiols (P-SH) were measured in fresh plasma by HPLC and spectrophotometry, respectively. Conversely, low molecular mass disulfides (LMM-SS) and S-thiolated proteins (RSSP) were analyzed in plasma samples obtained from blood treated with NEM. The P-SH were quantified by colorimetric reaction with Ellman's reagent [42]. LMM-SH, LMM-SS and RSSP were measured by fluorimetric HPLC after labeling of the - SH group with monobromobimane [43]. The Protein Thiolation Index (PTI) was calculated as the ratio between $S$-thiolated proteins and P-SH groups in plasma [44].

Cortisol and testosterone determinations in saliva. Saliva samples were collected using the Salivette collection device (Sarstedt Inc., Numbrecht, Germany) [45]. The subjects took a cotton wool tamponade out of a small tube, placed it in their mouth and chewed on it for 30-45 s, after which they put the tamponade back into the tube. Samples were then centrifuged and stored at $-30{ }^{\circ} \mathrm{C}$ until hormone determination using commercially available kits. Samples were assayed in duplicate for salivary cortisol and testosterone by ELISA kits, without modification of the manufacturers' recommended protocols (Mybiosource, San Diego, USA). For cortisol, the kit was based on competitive binding and the sensitivity was $0.049 \mathrm{ng} / \mathrm{ml}$, the intra-assay variation was less than $8 \%$ and the inter-assay variation was less than $10 \%$. For testosterone, the kit was based on the quantitative 
sandwich ELISA method and the sensitivity was $25 \mathrm{pmol} / \mathrm{L}$, the intra-assay and inter-assay variations were less than $15 \%$ for both.

\section{Soybean-enriched bread}

A well-known local bakery (Pariv Srl, Sinalunga, Siena, Italy) agreed to produce the soy-enriched bread and to supply all experimental subjects with two pieces (200 g each) of the bread every two days. This particular bread contains $20 \mathrm{mg} / 100 \mathrm{~g}$ of phytoestrogens derived from yellow soy as described by Ricci et al. (in preparation).

\section{Statistical analysis}

Data are presented as mean \pm SEM. Comparisons of variables analyzed at different time intervals were carried out by analysis of variance (ANOVA) with the Bonferroni multiple test with the factors Group (3 levels: Group 1, Group 2, Group 3) and Test (2 levels: Test 1, Test 2) [46]. The Wilcoxon matched pairs test was applied to data collected in a low number of subjects. All analyses were performed with Statistica ${ }^{\circledR}$ software. A level of $\mathrm{p} \leq 0.05$ was considered statistically significant. 


\section{RESULTS}

\section{Bread composition}

The bromatological composition of the bread, the energetic value and the content of phytoestrogens (genistein and daidzein) are reported in Table 1.

Table 1. Bromatological composition of the soybean-enriched bread per $100 \mathrm{~g}$ of the product. Phytoestrogens content and energetic value

\begin{tabular}{|c|c|}
\hline $\begin{array}{l}\text { Components } \\
(100 \mathrm{~g})\end{array}$ & $\%$ \\
\hline Proteins & $13.6 \%$ \\
\hline Lipids & $4.9 \%$ \\
\hline Carbohydrates & $34.9 \%$ \\
\hline Fiber & $7.1 \%$ \\
\hline $\begin{array}{l}\text { Phytoestrogens } \\
(\text { mean } \pm \text { SD) }\end{array}$ & $21.2 \pm 1.9$ \\
\hline $\begin{array}{l}\text { Energy } \\
\text { (kCal) }\end{array}$ & 251.68 \\
\hline
\end{tabular}

\section{Study subjects}

Out of the 30 women enrolled, 24 completed most of the experimental procedures. The baseline characteristics are shown in Table 2. The higher number of smokers present in Group 1 is to be noted. Analysis applied to BMI and BIA data (data not shown) showed no differences among groups or between tests.

Table 2. Baseline characteristics of subjects enrolled in the study divided into three groups depending on their menopausal state: Group 1: climacteric phase; Group 2: absence of menses for 1 to 5 years; Group 3: absence of menses for $>5$ years.

\begin{tabular}{|l|l|l|l|}
\hline Characteristics & $\begin{array}{l}\text { Group 1 } \\
(\mathbf{n = 8})\end{array}$ & $\begin{array}{l}\text { Group 2 } \\
(\mathbf{n = 8})\end{array}$ & $\begin{array}{l}\text { Group 3 } \\
(\mathbf{n = 8})\end{array}$ \\
\cline { 2 - 4 } & Mean \pm SEM & Mean \pm SEM & Mean \pm SEM \\
\hline Age (years) & $50.5 \pm 1.1$ & $55.3 \pm 0.7$ & $59.4 \pm 2.0$ \\
\hline Weight $(\mathrm{kg})$ & $64.5 \pm 3.5$ & $66.4 \pm 4.6$ & $64.1 \pm 2.3$ \\
\hline Height $(\mathrm{m})$ & $1.64 \pm 0.02$ & $1.63 \pm 0.02$ & $1.62 \pm 0.02$ \\
\hline Smoker & $50 \%$ & $20 \%$ & $10 \%$ \\
\hline
\end{tabular}

\section{Questionnaires}


Results of the menopause-related questionnaires are reported in Figure 1. There was a significant decrease in the number of hot flushes/day from Test 1 to Test $2(\mathrm{p}<0.01)$. The intensity of HF and the sexual desire did not change from Test 1 to Test 2. For night sleep quality, there was a marginally significant interaction $(\mathrm{p}=0.06)$ due to Group 3 reporting a significant improvement from Test 1 to Test $2(\mathrm{p}<0.01)$.

\section{POMS}

As shown in Table 3, most of the values obtained from the POMS questionnaire during Test 1 were outside the normal range (more or less than 55). The consumption of soy-enriched bread resulted in a significant decrease (improvement) of the following subscales independent of the groups: TensionAnxiety $\quad(p=0.01)$, Depression-Dejection $\quad(p=0.01)$, Fatigue-Inertia $\quad(p=0.006)$, ConfusionBewilderment $(\mathrm{p}<0.001)$. The Anger-Hostility and Vigor-Activity subscales did not show significant changes from Test 1 to Test 2 .

Table 3. Profile of Mood States (POMS) determined in the three experimental groups: Group 1: climacteric phase; Group 2: absence of menses for 1 to 5 years; Group 3: absence of menses for $>5$ years. Abbreviations: T-A (Tension-Anxiety), D-D (Depression-Dejection), A-H (Anger-Hostility), V-A (Vigor-Activity), F-I (Fatigue-Inertia), C-B (ConfusionBewilderment). Reference value is lower than 55 in T-A, D-D, A-H, F-I, C-B; higher than 55 in V-A

\begin{tabular}{|c|c|c|c|c|c|c|c|}
\hline & & POMS T-A & POMS D-D & POMS A-H & POMS V-A & POMS F-I & POMS C-B \\
\hline Grou & $\begin{array}{l}\text { Test } 1 \\
\text { Test } 2\end{array}$ & & & $\begin{array}{l}54.25 \pm 4.68 \\
51.50 \pm 4.77\end{array}$ & $\begin{array}{l}48.50 \pm 2.87 \\
53.75 \pm 3.34\end{array}$ & $\begin{array}{l}62.50 \pm 5.75 \\
56.50 \pm 4.27\end{array}$ & $\begin{array}{l}60.00 \pm 4.05 \\
50.37 \pm 2.84\end{array}$ \\
\hline Group 2 & $\begin{array}{l}\text { Test } 1 \\
\text { Test } 2\end{array}$ & & & & & $\begin{array}{l}62.22 \pm 4.75 \\
57.89 \pm 5.66\end{array}$ & $\begin{array}{l}58.22 \pm 4.02 \\
53.33 \pm 4.52\end{array}$ \\
\hline G & $\begin{array}{l}\text { Test } 1 \\
\text { Test } 2 \\
\end{array}$ & $\begin{array}{l}57.62 \pm 5.81 \\
51.12 \pm 3.58\end{array}$ & $\begin{array}{l}58.00 \pm 5.81 \\
51.12 \pm 3.58\end{array}$ & $\begin{array}{l}59.37 \pm 5.14 \\
53.00 \pm 2.42\end{array}$ & $\begin{array}{l}51.75 \pm 4.46 \\
54.50 \pm 3.72\end{array}$ & $\begin{array}{l}63.87 \pm 5.67 \\
56.75 \pm 3.98\end{array}$ & $\begin{array}{l}60.75 \pm 4.77 \\
48.37 \pm 3.34\end{array}$ \\
\hline
\end{tabular}

\section{SF-36}

The aim of the SF-36 questionnaire is to give information about the quality of life of the subjects.

The components can be grouped into two main components, the Physical (PCS-36) and the Mental (MCS-36). For the PCS-36 components (Fig 2), treatment induced a significant increase (improvement) from Test 1 to Test 2 in physical functioning (PF, Test: $\mathrm{p}<0.01)$ and role physical (RP, Test: $\mathrm{p}=0.05)$, while bodily pain showed a significant interaction $(\mathrm{BP}$, Group $\mathrm{x}$ Test: $\mathrm{p}=0.03)$ due to 
the increase from Test 1 to Test 2 in Group 2. There was no significant difference in general health (GH). For the MCS-36 components, significance was found in social functioning and role emotional (SF, RE, Test: $\mathrm{p}<0.002$ and $\mathrm{p}=0.02$ respectively) due to an increase from Test 1 to Test 2; vitality (V) and mental health $(\mathrm{MH})$ did not show significant changes.

\section{Pain evaluation. VAS and QUID}

Chronic pain was present in 19 subjects. Only women reporting pain were included in the analysis. VAS was considered separately in the morning, afternoon and night. The morning and afternoon pain intensity decreased from Test 1 to Test 2, as shown by significance of the factor Test $(\mathrm{p}=0.007$ and $\mathrm{p}<0.01$, respectively). No changes were found for the night determination (Table 4).

ANOVA applied to the QUIDs component revealed a significant effect of Group ( $\mathrm{p}=0.01)$ and Test $(\mathrm{p}=0.01)$ due to the higher levels in Group 2 than in Groups 1 and $3(\mathrm{p}<0.01$ both) and the decrease from Test 1 to Test 2 (Table 4). For the PRIr-T, there was significance of the factor Group $(\mathrm{p}<0.02)$ due to the higher levels in Group 2 than in Groups 1 and 3 ( $p<0.05$ both). No significant changes were recorded in the other components and PPI.

Table 4. Pain parameters determined in the three experimental groups (only women with pain were considered): Group $1(n=6)$ : climacteric phase; Group $2(n=8)$ : absence of menses for 1 to 5 years; Group 3 ( $n=5)$ : absence of menses for $>5$ years. Visual Analogue Scale (VAS: 0-10) and Italian Pain Questionnaire (QUID), abbreviations: s (sensorial), a (affective), e (emotional), m (miscellaneous), PRI-T (Pain Rating Index rank-Total), PPI (Present Pain Intensity, 0-5).

Values are reported as Mean \pm SEM

\begin{tabular}{|c|c|c|c|c|c|c|c|}
\hline \multicolumn{2}{|l|}{ VAS } & VAS morning & \multicolumn{2}{|c|}{ g VAS afternoon } & \multirow{2}{*}{$\begin{array}{l}\text { VAS night } \\
3.00 \pm 1.15 \\
2.00 \pm 1.00\end{array}$} & & \\
\hline Group 1 & $\begin{array}{l}\text { Test } 1 \\
\text { Test } 2\end{array}$ & $\begin{array}{l}4.14 \pm 1.24 \\
2.57 \pm 1.04\end{array}$ & $\begin{array}{l}3.28 \pm 1 \\
1.43 \pm 0 \\
\end{array}$ & & & & \\
\hline Group 2 & $\begin{array}{l}\text { Test } 1 \\
\text { Test } 2\end{array}$ & $\begin{array}{l}5.37 \pm 1.02 \\
3.75 \pm 0.67\end{array}$ & $\begin{array}{l}3.00 \pm 1 \\
3.25 \pm 0\end{array}$ & & $\begin{array}{l}2.87 \pm 1.11 \\
2.50 \pm 0.84\end{array}$ & & \\
\hline Group 3 & $\begin{array}{l}\text { Test } 1 \\
\text { Test } 2 \\
\end{array}$ & $\begin{array}{l}4.40 \pm 1.33 \\
1.00 \pm 0.63 \\
\end{array}$ & $\begin{array}{l}5.20 \pm 1 \\
1.00 \pm 0 \\
\end{array}$ & & $\begin{array}{l}1.20 \pm 1.20 \\
1.40 \pm 0.60 \\
\end{array}$ & & \\
\hline QUID & & QUIDs & QUIDa & QUIDe & QUIDm & PRIr-T & PPI \\
\hline Group 1 & $\begin{array}{l}\text { Test } 1 \\
\text { Test } 2 \\
\end{array}$ & $\begin{array}{ll}3.33 \pm 0.76 & 0 \\
1.33 \pm 0.33 & 0 \\
\end{array}$ & $\begin{array}{l}0.00 \pm 0.00 \\
0.17 \pm 0.17\end{array}$ & $\begin{array}{l}2.17 \pm 0.54 \\
1.67 \pm 0.67 \\
\end{array}$ & $\begin{array}{l}0.17 \pm 0.17 \\
0.00 \pm 0.00\end{array}$ & $\begin{array}{l}5.67 \pm 1.38 \\
3.17 \pm 0.83 \\
\end{array}$ & $\begin{array}{l}1.33 \pm 0.21 \\
1.33 \pm 0.42 \\
\end{array}$ \\
\hline Group 2 & $\begin{array}{l}\text { Test } 1 \\
\text { Test } 2\end{array}$ & $\begin{array}{l}7.62 \pm 1.29 \\
5.37 \pm 1.47\end{array}$ & $\begin{array}{l}3.50 \pm 1.12 \\
2.12 \pm 1.31\end{array}$ & $\begin{array}{l}3.87 \pm 1.02 \\
1.87 \pm 0.64\end{array}$ & $\begin{array}{l}2.50 \pm 1.07 \\
1.37 \pm 1.24\end{array}$ & $\begin{array}{l}17.50 \pm 3.40 \\
10.75 \pm 3.90\end{array}$ & $\begin{array}{l}2.00 \pm 0.38 \\
1.50 \pm 0.27\end{array}$ \\
\hline Group 3 & $\begin{array}{l}\text { Test } 1 \\
\text { Test } 2\end{array}$ & $\begin{array}{l}3.80 \pm 1.74 \\
1.40 \pm 0.68\end{array}$ & $\begin{array}{l}3.00 \pm 2.32 \\
0.60 \pm 0.60\end{array}$ & $\begin{array}{l}2.00 \pm 0.55 \\
1.20 \pm 0.97\end{array}$ & $\begin{array}{l}0.80 \pm 0.80 \\
0.40 \pm 0.40\end{array}$ & $\begin{array}{l}9.60 \pm 5.06 \\
3.60 \pm 1.69\end{array}$ & $\begin{array}{l}1.40 \pm 0.40 \\
1.00 \pm 0.45\end{array}$ \\
\hline
\end{tabular}

\section{Test of Attentional Performance}


ANOVA applied to reaction time values (Fig. 3A) revealed significance of Group ( $\mathrm{p}=0.03$ ) and Test $(\mathrm{p}=0.002)$ due to the shorter reaction time in Group 2 than in Group $3(\mathrm{p}<0.01)$ and the shorter reaction time in Test 2 than in Test 1.

For the number of correct responses ( $\%$ of total responses, Fig. 3B), the significance of Test ( $\mathrm{p}=0.01)$ indicates that, independently of the group of women observed, the performance was significantly improved from Test 1 to Test 2.

\section{Daidzein and genistein levels in urine}

Daidzein and genistein were measured in urine before (Test 1) and after the consumption of soyenriched bread for 30 days (Test 2). The measured values normalized for creatinine content are reported in Figure 4. For both daidzein and genistein, ANOVA revealed a significant effect of Test $(\mathrm{p}=0.001, \mathrm{p}=0.008$ respectively) due to the increase in urinary levels of both compounds from Test 1 to Test 2 in all groups.

\section{Thiols and disulfides in red blood cells and plasma}

The potential effect of the soy-enriched bread on the antioxidant pattern was evaluated by measuring the levels of thiols and their ratio with disulfides in both red blood cells (RBC) and plasma. Since not all women were tested for these parameters, the analysis did not consider the factor Group. The RBC content of GSH and GSSG was in the normal range and was not influenced by consumption of the functional bread (Table 5). Consequently, the GSH/GSSG ratio was also unvaried.

Table 5. Glutathione (GSH) and glutathione disulfide (GSSG) levels in red blood cells (RBC). Women $\mathrm{n}=9$

\begin{tabular}{l|lll}
\hline & $\begin{array}{l}\text { GSH } \\
(\mathbf{n m o l} / \mathbf{m g ~ H b})\end{array}$ & $\begin{array}{l}\text { GSSG } \\
(\mathbf{n m o l} / \mathbf{m g} \mathbf{H b})\end{array}$ & GSH/GSSG \\
\hline Test 1 & $5.52 \pm 0.26$ & $0.011 \pm 0.011$ & $586.67 \pm 68.74$ \\
\hline Test 2 & $6.07 \pm 0.34$ & $0.012 \pm 0.012$ & $546.45 \pm 59.86$ \\
\hline
\end{tabular}

In plasma there was a significant increase of thiols and LMM-SH (Table 6). The Wilcoxon matched pairs test revealed significance for P-SH, Cys, CysGly, Hcys, CySS, CySSGly and $\gamma$-GluCys (Z=2.84, 
$\mathrm{p}=0.004 ; \mathrm{Z}=1.98, \mathrm{p}<0.05 ; \mathrm{Z}=2.57, \mathrm{p}<0.01 ; \mathrm{Z}=2.40, \mathrm{p}<0.02 ; \mathrm{Z}=2.67,0.01 ; \mathrm{Z}=2.13, \mathrm{p}<0.03$ and $\mathrm{Z}=2.57, \mathrm{p}<0.01$, respectively) due to higher levels in Test 2 than in Test 1 .

Table 6. Plasma thiols and disulfides determination. Women $n=11 .{ }^{*} p<0.05$ and $* * p<0.01$, Test 2 vs Test 1.

Abbreviations: Cys (cysteine), CysGly (cysteinylglycine), Hcys (homocysteine), $\gamma$-GluCys ( $\gamma$-glutamylcysteine), GSH (glutathione), P-SH (protein sulfhydryl groups), LMM-SS (low molecular weight disulfide), CySS (cystine), CySSGly (cystinylglycine), HcySS (homocysteine), $\gamma$-GluCySS ( $\gamma$-glutamylcystine), GSSG (glutathione disulfide), RSSP (S-thiolated proteins), CySSP (protein mixed disulfides with cysteine), CyGlySSP (protein mixed disulfides with cysteinylglycine), HcySSP (protein mixed disulfides with homocysteine), $\gamma$-GluCySSP (protein mixed disulfides with $\gamma$-glutamylcysteine), GSSP (protein mixed disulfides with glutathione), PTI (Protein Thiolation Index)

\section{Hormones in saliva}

\begin{tabular}{|l|llllll}
\hline Reduced Thiols & P-SH & Cys & CysGly & Hcys & $\gamma$-GluCys & GSH \\
\hline Test 1 & $401.17 \pm 8.13$ & $9.59 \pm 0.60$ & $1.24 \pm 0.11$ & $0.11 \pm 0.01$ & $0.04 \pm 0.003$ & $1.66 \pm 0.24$ \\
& & & & & & \\
\hline Test 2 & $437.73 \pm 8.30^{* *}$ & $11.3 \pm 0.58^{*}$ & $1.89 \pm 0.23^{* *}$ & $0.17 \pm 0.01^{*}$ & $0.05 \pm 0.004$ & $2.00 \pm 0.16$ \\
\hline LMM-SS & CySS & CySSGly & HcySS & $\gamma$-GluCySS & GSSG & \\
\hline Test 1 & $61.40 \pm 2.84$ & $5.77 \pm 0.27$ & $0.99 \pm 0.11$ & $0.67 \pm 0.03$ & $0.84 \pm 0.10$ & \\
\hline Test 2 & $90.27 \pm 6.63^{* *}$ & $6.48 \pm 0.30^{*}$ & $1.13 \pm 0.14$ & $0.90 \pm 0.06^{* *}$ & $0.89 \pm 0.07$ & \\
\hline RSSP & CySSP & CyGlySSP & HcySSP & $\gamma$-GluCySSP & GSSP & PTI \\
\hline Test 1 & $127.52 \pm 7.19$ & $12.01 \pm 0.9$ & $4.92 \pm 0.60$ & $1.41 \pm 0.12$ & $2.11 \pm 0.18$ & $0.38 \pm 0.02$ \\
\hline Test 2 & $138.04 \pm 8.91$ & $11.57 \pm 0.55$ & $4.99 \pm 0.45$ & $1.51 \pm 0.11$ & $2.45 \pm 0.14$ & $0.36 \pm 0.02$ \\
\hline
\end{tabular}

Due to the low number of samples, groups were not considered for these parameters. The Wilcoxon matched pairs test applied to cortisol values revealed a significant increase from Test 1 to Test 2 $(\mathrm{n}=12$, mean: $2.23 \pm 0.46$ vs $4.57 \pm 0.78 ; \mathrm{Z}=2.04, \mathrm{p}=0.041$ ); there was no significance for testosterone ( $\mathrm{n}=13$, mean: $0.19 \pm 0.02$ vs $0.14 \pm 0.02 ; \mathrm{Z}=0.94, \mathrm{p}=0.354)$. 


\section{DISCUSSION}

The main result of the present experiment was the positive change in most of the parameters considered in climacteric/menopausal women after 30 days of consumption of soy-enriched bread. Behavioral, psychological and attentional tests all showed significant improvement in the various parameters such as hot flushes, mood, pain, quality of life questionnaires and reaction time performance. Interestingly, most of the changes were highly significant but present in one or another group, suggesting a different responsiveness of the women to phytoestrogens exposure depending on their menopausal status. The involvement of the soy-enriched bread in these changes was supported by the significant increase in the urinary levels of genistein and daidzein, the main phytoestrogens present in soy.

Soy is an important product commonly used in human and animal feeding because of its high protein content. It is often used to extract phytoestrogens to be commercialized as supplements to fight menopausal symptoms [21]; nevertheless, their use among women in menopause is not very common. Therefore, since the average age of menopausal onset is 50 years and the lifespan of women in Italy is over 80 years, about one third of a woman's life would pass with very low estrogen levels and a high risk of hypo-estrogen-related diseases, from cardiovascular to neuronal ones [47].

The study of foods with known amounts of phytoestrogens must be considered a serious effort to provide a solution to estrogen depletion. The presence in soy of genistein and daidzein (the main isoflavones), as well as other nutrients, is well known $[48,49,50,51,52]$. Thus, we considered the possibility to provide phytoestrogens not as an extract, as commonly available in many commercial products, but as whole beans in order to maintain the 'natural context' of the compounds essential to their functions. The soy-enriched bread used in the present experiment was prepared so as to supply $20 \mathrm{mg} / 100 \mathrm{gr}$ of phytoestrogens, about $14 \mathrm{mg} / 100 \mathrm{mg}$ of proteins and low levels of lipids and carbohydrates. As expected the presence of isoflavones in the urine clearly increased after 30 days of treatment, suggesting their presence in the circulation and distribution among tissues $[53,54]$. 
We tested the soy-enriched bread in three groups of women with different menopausal condition: women in the climacteric period with 'irregular' menstrual cycles due to the estrogen fluctuations (Group 1); women in menopause, i.e. with the absence of menses for 1 to 5 years (Group 2); women with the absence of menses for more than 5 years (Group 3). None of the women had undergone hormone replacement therapy, and thus we expected to have different physiological estrogen depletion levels. Interestingly although not many years separated one group from the others, the groups differed already during the first test in various parameters like hot flushes, pain scores and reaction time in the Test of Attentional Performance. In particular, the VAS scores and QUID values were higher in Group 2 than in the others, and Group 2 showed better performance in the attentional tests, with shorter reaction times. This is interesting since it confirms that this group, in menopause from 1 to 5 years, is 'more reactive' than the others.

Phytoestrogens mimic several actions mediated by ER $\alpha$ and ER $\beta$ estrogen receptors [55], albeit with a different ability to induce their activation [56]; indeed, phytoestrogens display a substantially higher affinity for ER $\beta$ [57] which appears to be associated with antiproliferative and anticarcinogenic effects [58,59], unlike ER $\alpha$ [60]. Daidzein, in particular, can cross the blood-brain barrier and a detectable concentration has been reported in brain within the first hour of its administration [54] including the hippocampus, striatum, cortex, cerebellum, brainstem and hypothalamus. The effects of phytoestrogens are clearly demonstrated in the present study by the decrease in reaction time and the higher percentage of correct answers present in all groups at the second Test of Attentional Performance, 30 days after regular consumption of soy-enriched bread. This type of test analyzes the subject's ability to suppress an inadequate response (no-go) and to react in the presence of stimuli activating the paradigm of a go/no-go complex [32]. This ability requires significant interventions by the central nervous system. These changes were not induced by repetition of the test, since 30 days of delay from the first to the second test are enough to cancel the memory of the event.

Hot flushes are very common in menopausal women and can impair a woman's quality of life until 7-8 years after the climacteric period. They are not present in all women and can be modulated by 18 
phytoestrogens [47]. In the present study, the consumption of soy-enriched bread decreased the daily frequency of hot flushes in all groups. This decrease can be attributed to specific effects on central thermoregulatory systems but also to non-specific effects related to common life aspects, as shown by the changes in the physical and general health status (SF-36 questionnaire).

Pain, and particularly chronic pain, is very common in the general population, affecting $30 \%$ of women [61,62]. At menopausal age, pain can easily affect a woman's behavior, lowering the time spent walking and moving in general. Thus, the fact that pain was reduced in the present study, particularly in the morning and afternoon (VAS score and QUID sensorial component), is of particular importance. Pain in these women is not of high intensity, only rarely reaching the VAS score of 5. However, it can be present in different parts of the body and can be difficult to treat with analgesics. This kind of pain can be the result of general inflammation often present at the subclinical level. Hence, phytoestrogens are suitable to play a positive role in pain control since several studies have shown their anti-inflammatory action $[63,64]$. Sakamoto et al. examined the effect of daidzein on the markers of pro-inflammatory cytokines in co-cultures of 3T3L1 adipocytes and RAW264 macrophages [65]. Daidzein $(25 \mu \mathrm{M})$ treatment significantly inhibited the mRNA expression of the pro-inflammatory cytokines CCL2 and IL6 in adipocytes induced by co-culture. The antiinflammatory effect of daidzein has also been examined by using TNF $\alpha$-treated $(20 \mathrm{ng} / \mathrm{ml})$ murine MLE-12 epithelial cells [66].

Isoflavones are supposed to exert some beneficial effects by virtue of their antioxidant properties [51]. In order to investigate this possibility, the thiol to disulfide ratio was measured in blood of the enrolled women at the beginning of the soy-enriched bread consumption and after 30 days. There was no significant variation in the GSH/GSSG ratio (a widely accepted biomarker of oxidative stress) in $\mathrm{RBC}$ or in the thiol composition in plasma. Indeed, the thiol to disulfide ratio for all the physiological molecules occurring in plasma indicates that the measured parameters in menopausal women are within the range of the same values measured in the rest of the population $[67,68]$; moreover, after 1month of soy-enriched diet, there was a slight but significant increase in both the reduced and oxidized 
forms (namely LMM-SS) of some thiols. Thus, it can be inferred that this kind of diet did not have a strong impact on the extracellular thiol/disulfide balance.

\section{CONCLUSIONS}

Our multifactorial approach to the study of menopause confirms the beneficial effect of phytoestrogens on most of the parameters taken into consideration. The physical status and mood and cognition were affected by phytoestrogens. Their presence in a 'common' food such as bread allows their consumption without any pharmacological approach.

The limitations of the study are the low number of subjects and the short duration of the treatment (30 days). However, we would expect an even greater and longer-lasting effect by supplying phytoestrogens (also from plant sources other than soybean) for a longer period.

\section{Potential Clinical Value}

Aging is accompanied by several changes in the body. The brain is particularly affected by the estrogen decline in women. Herein we describe the improvement of mental and physical parameters in women of different menopausal age after 30 days of regular consumption of soy-enriched bread. The present data can be used to convince physicians to suggest the inclusion of products containing soy in the diet of women in menopause. 


\section{FIGURE LEGENDS}

FIG. 1

Number of hot flushes, intensity of hot flushes, sexual desire and sleep quality in the three groups of women before (Test 1) and after (Test 2) 30 days of daily intake of bread enriched with $20 \mathrm{mg} / 100 \mathrm{~g}$ of soy. $\mathrm{n}=24{ }^{*} \mathrm{p}<0.05$ Test 2 vs baseline levels Test 1 .

\section{FIG. 2}

SF-36. The enrolled women filled in the questionnaire before (Test 1) and after (Test 2) 30 days of daily intake of bread enriched with $20 \mathrm{mg} / 100 \mathrm{~g}$ of soy. Eight scales referred to the quality of life. $\mathrm{n}=24 .{ }^{*} \mathrm{p}<0.05$ Test 2 vs Test 1; abbreviations: PF: physical functioning, RP: role physical, BP: bodily pain, GH; general health, V: vitality, SF: social functioning, RE: role emotional, MH: mental health.

FIG. 3

Test of Attentional Performance. Mean value of the reaction time in seconds and number of correct answers in percentage before (Test 1) and after (Test 2) 30 days of daily intake of bread enriched with $20 \mathrm{mg} / 100 \mathrm{~g}$ of soy. $\mathrm{n}=24 .{ }^{*} \mathrm{p}<0.05 ; * * \mathrm{p}<0.01$ Test 2 vs Test 1.

FIG. 4

Urinary levels of daidzein and genistein. The first-void urine of the women enrolled in the study was analyzed for the contents of glucuronidated daidzein and genistein by means of HPLC. The analysis was carried out before (Test 1) and after (Test 2) 30 days of daily intake of bread enriched with 20 mg/100 g of soy. $\mathrm{n}=24 .{ }^{*} \mathrm{p}<0.05$ Test 2 vs baseline levels Test 1. 
Acknowledgements. The authors thank the University of Siena for funding this research, Pariv Srl for the collaboration in preparing and producing the special bread, Dr Valeria Bachiocco for the critical reading of the manuscript and Dr Peter Christie for the English language revision.

Financial Disclosures/Conflicts of Interest: All authors declare no conflict of interest. 


\section{REFERENCES}

[1] R. Lauretta, M. Sansone, A. Sansone, F. Romanelli, M. Appetecchia, Gender in endocrine diseases: Role of sex gonadal hormones, Int. J. Endocrinol. (2018). https://doi.org/10.1155/2018/4847376.

[2] T.A. Takahashi, K.M. Johnson, Menopause, Med. Clin. North Am. 99 (2015) 521-534. https://doi.org/10.1016/j.mcna.2015.01.006.

[3] A. Tufano, P. Marzo, R. Enrini, L. Morricone, F. Caviezel, B. Ambrosi, Anthropometric, hormonal and biochemical differences in lean and obese women before and after menopause, J. Endocrinol. Invest. 27 (2004) 648-653. https://doi.org/10.1007/BF03347497.

[4] R.A. Lobo, S.R. Davis, T.J. De Villiers, A. Gompel, V.W. Henderson, H.N. Hodis, M.A. Lumsden, W.J. Mack, S. Shapiro, R.J. Baber, Prevention of diseases after menopause, Climacteric. 17 (2014) 540-556. https://doi.org/10.3109/13697137.2014.933411.

[5] B. Guarnieri, Sleep disorders and cognitive alterations in women, Maturitas. 126 (2019) 2527. https://doi.org/10.1016/j.maturitas.2019.04.214.

[6] N. Santoro, C.N. Epperson, S.B. Mathews, Menopausal symptoms and their management, Endocrinol. Metab. Clin. North Am. $44 \quad$ (2015) 497-515. https://doi.org/10.1016/j.ecl.2015.05.001.

[7] L. Newson, Menopause and cardiovascular disease, Post Reprod. Heal. 24 (2018) 44-49. https://doi.org/10.1177/2053369117749675.

[8] H. Sumino, S. Ichikawa, A. Yoshida, M. Murakami, T. Kanda, H. Mizunuma, T. Sakamaki, M. Kurabayashi, Effects of hormone replacement therapy on weight, abdominal fat distribution, and lipid levels in Japanese postmenopausal women, Int. J. Obes. 27 (2003) 10441051. https://doi.org/10.1038/sj.ijo.0802371.

[9] C.A. Stuenkel, Vasomotor and related menopause symptoms, Clin. Obstet. Gynecol. 61 (2018) 433-446. https://doi.org/10.1097/GRF.0000000000000385. 
[10] J.E. Rossouw, G.L. Anderson, R.L. Prentice, A.Z. LaCroix, C. Kooperberg, M.L. Stefanick, R.D. Jackson, S.A.A. Beresford, B. V. Howard, K.C. Johnson, J.M. Kotchen, J. Ockene, Risks and benefits of estrogen plus progestin in healthy postmenopausal women: Principal results from the women's health initiative randomized controlled trial, J. Am. Med. Assoc. 288 (2002) 321-333. https://doi.org/10.1001/jama.288.3.321.

[11] R.M. Kutlesic, J. Popovic, M. Stefanovic, P. Vukomanovic, B. Lukic, G. Lilic, Alternatives of menopausal hormone therapy, Med. Pregl. $69 \quad$ (2016) 177-182. https://doi.org/10.2298/mpns1606177k.

[12] A.V. Rao, S. Agarwal, Role of antioxidant lycopene in cancer and heart disease, J. Am. Coll. Nutr. 19 (2000) 563-569. https://doi.org/10.1080/07315724.2000.10718953.

[13] M.R. Lambert, T.M. Edwards, Hormonally active phytochemicals and vertebrate evolution, Evol. Appl. 10 (2017) 419-432. https://doi.org/10.1111/eva.12469.

[14] M.J.R. Howes, N.S.L. Perry, C. Vásquez-Londoño, E.K. Perry, Role of phytochemicals as nutraceuticals for cognitive functions affected in ageing, Br. J. Pharmacol. 177 (2020) 12941315. https://doi.org/10.1111/bph.14898.

[15] V. B. Gencel, M. M. Benjamin, S. N. Bahou, R. A. Khalil, Vascular effects of phytoestrogens and alternative menopausal hormone therapy in cardiovascular disease, Mini-Reviews Med. Chem. 12 (2012) 149-174. https://doi.org/10.2174/138955712798995020.

[16] K. Taku, M.K. Melby, F. Kronenberg, M.S. Kurzer, M. Messina, Extracted or synthesized soybean isoflavones reduce menopausal hot flash frequency and severity: Systematic review and meta-analysis of randomized controlled trials, Menopause. 19 (2012) 776-790. https://doi.org/10.1097/gme.0b013e3182410159.

[17] Y.B. Zhang, W.H. Chen, J.J. Guo, Z.H. Fu, C. Yi, M. Zhang, X.L. Na, Soy isoflavone supplementation could reduce body weight and improve glucose metabolism in non-Asian postmenopausal women-A meta-analysis, Nutrition. $29 \quad$ (2013) 8-14. https://doi.org/10.1016/j.nut.2012.03.019. 
[18] S.D. Desmawati, Phytoestrogens and their health effect, Open Access Maced. J. Med. Sci. 7 (2019) 495-499. https://pubmed.ncbi.nlm.nih.gov/30834024/.

[19] S. Barnes, The biochemistry, chemistry and physiology of the isoflavones in soybeans and their food products, Lymphat. Res. Biol. $8 \quad$ (2010) 89-98. https://doi.org/10.1089/1rb.2009.0030.

[20] W.Z. Zhengkang, G. Wang, W. Yao, Isoflavonic phytoestrogens-new prebiotics for farm animals: a review on research in China, Curr. Issues Intest. Microbiol. 7 (2006) 53-60. https://pubmed.ncbi.nlm.nih.gov/16875419/ (accessed November 2, 2020).

[21] T. Zhou, C. Meng, P. He, Soy isoflavones and their effects on xenobiotic metabolism, Curr. Drug Metab. 20 (2018) 46-53. https://doi.org/10.2174/1389200219666180427170213.

[22] L. Křížová, K. Dadáková, J. Kašparovská, T. Kašparovský, Isoflavones, Molecules. 24 (2019). https://doi.org/10.3390/molecules24061076.

[23] E. Anupongsanugool, S. Teekachunhatean, N. Rojanasthien, S. Pongsatha, C. Sangdee, Pharmacokinetics of isoflavones, daidzein and genistein, after ingestion of soy beverage compared with soy extract capsules in postmenopausal Thai women, BMC Clin. Pharmacol. 5 (2005). https://doi.org/10.1186/1472-6904-5-2.

[24] P. Basu, S. Sunny, C. Maier, Estrogenic and antiestrogenic activities of commercial dietary supplements containing herbal ingredients and isoflavones, Int. J. Pharm. Pharm. Sci. 8 (2016) 307-312. https://doi.org/10.22159/ijpps.2016v8i11.14687.

[25] A.H.H. Alexander, V. Sirotkin, Phytoestrogens and their effects, Eur. J. Pharmacol. 741 (2014) 230-236. https://doi.org/10.1016/j.ejphar.2014.07.057.

[26] I. Paterni, C. Granchi, J.A. Katzenellenbogen, F. Minutolo, Estrogen receptors alpha (ER $\alpha)$ and beta (ER $\beta)$ : Subtype-selective ligands and clinical potential, Steroids. 90 (2014) 13-29. https://doi.org/10.1016/j.steroids.2014.06.012.

[27] S. Lecomte, F. Demay, F. Ferrière, F. Pakdel, Phytochemicals targeting estrogen receptors: Beneficial rather than adverse effects?, Int. J. Mol. Sci. 18 (2017). 
https://doi.org/10.3390/ijms18071381.

[28] C.-J. Hsieh, Y.-L. Hsu, Y.-F. Huang, E.-M. Tsai, Molecular mechanisms of anticancer effects of phytoestrogens in breast cancer, Curr. Protein Pept. Sci. 19 (2018). https://doi.org/10.2174/1389203718666170111121255.

[29] D.P. Kotler, S. Burastero, J. Wang, R.N. Pierson, Prediction of body cell mass, fat-free mass, and total body water with bioelectrical impedance analysis: Effects of race, sex, and disease, Am. J. Clin. Nutr. 64 (1996) 489S-497S. https://doi.org/10.1093/ajcn/64.3.489S.

[30] D.M. McNair, M. Lorr, L.F. Droppelman, EDITS Manual for the Profile of Mood States, Educ. Ind. Test. Serv. - San Diego. (1971).

[31] M. Morfeld, C. Petersen, A. Krüger-Bödeker, S. von Mackensen, M. Bullinger, The assessment of mood at workplace - psychometric analyses of the revised Profile of Mood States $\begin{array}{lllll}\text { (POMS) } & \text { questionnaire, } & \text { Psychosoc. } & \text { Med. } & 4\end{array}$ https://pubmed.ncbi.nlm.nih.gov/19742299.

[32] G. Fontani, F. Corradeschi, A. Felici, F. Alfatti, S. Migliorini, L. Lodi, Cognitive and physiological effects of Omega-3 polyunsaturated fatty acid supplementation in healthy subjects, Eur. J. Clin. Invest. 35 (2005) 691-699. https://doi.org/10.1111/j.13652362.2005.01570.x.

[33] G. Apolone, P. Mosconi, The Italian SF-36 Health Survey: Translation, validation and norming, J. Clin. Epidemiol. 51 (1998) 1025-1036. https://doi.org/10.1016/S08954356(98)00094-8.

[34] E.C. Huskisson, J. Jones, P.J. Scott, Application of visual-analogue scales to the measurement of functional capacity, Rheumatology. $15 \quad$ (1976) 185-187. https://doi.org/10.1093/rheumatology/15.3.185.

[35] G. De Benedittis, R. Massel, R. Nobili, A. Pieri, The Italian pain questionnaire, Pain. 33 (1988) 53-62. https://doi.org/10.1016/0304-3959(88)90203-5.

[36] P. Zimmermann, B.Fimm, Batteria di test per l'esame dell'attenzione, Tr. It., 1992. 
[37] X. Xu, H.J. Wang, P.A. Murphy, L. Cook, S. Hendrich, Daidzein is a more bioavailable soymilk isoflavone than is genistein in adult women, J. Nutr. 124 (1994) 825-832. https://doi.org/10.1093/jn/124.6.825.

[38] G. Montero, G. Günther, K. Valdés, F. Arriagada, J. Morales, An HPLC method for the determination of isoflavones and the evaluation of their antioxidant capacity in both homogeneous and microheterogeneous systems, J. AOAC Int. 101 (2018) 235-241. https://doi.org/10.5740/jaoacint.17-0104.

[39] Max Jaffé (1841-1911). Nature. 148 (1941) 110. https://doi.org/10.1038/148110d0.

[40] D. Giustarini, I. Dalle-Donne, A. Milzani, R. Rossi, Detection of glutathione in whole blood after stabilization with N-ethylmaleimide, Anal. Biochem. 415 (2011) 81-83. https://doi.org/10.1016/j.ab.2011.04.013.

[41] D. Giustarini, I. Dalle-Donne, A. Milzani, P. Fanti, R. Rossi, Analysis of GSH and GSSG after derivatization with N-ethylmaleimide, Nat. Protoc. $8 \quad$ (2013) 1660-1669. https://doi.org/10.1038/nprot.2013.095.

[42] D. Giustarini, S. Lorenzini, R. Rossi, D. Chindamo, P. Di Simplicio, R. Marcolongo, Altered thiol pattern in plasma of subjects affected by rheumatoid arthritis, Clin. Exp. Rheumatol. 23 (2005) 205-212. https://pubmed.ncbi.nlm.nih.gov/15895891.

[43] P. Fanti, D. Giustarini, R. Rossi, S.E.D. Cunningham, F. Folli, K. Khazim, J. Cornell, E. Matteucci, S. Bansal, Dietary intake of proteins and calories is inversely associated with the oxidation state of plasma thiols in end-stage renal disease patients, J. Ren. Nutr. 25 (2015) 494-503. https://doi.org/10.1053/j.jrn.2015.06.003.

[44] D. Giustarini, I. Dalle-Donne, S. Lorenzini, E. Selvi, G. Colombo, A. Milzani, P. Fanti, R. Rossi, Protein thiolation index (PTI) as a biomarker of oxidative stress, Free Radic. Biol. Med. 53 (2012) 907-915. https://doi.org/10.1016/j.freeradbiomed.2012.06.022.

[45] M. Katsumata, K. Hirata, H. Inagaki, Y. Hirata, T. Kawada, [Evaluation of new saliva collection device for determination of salivary cotinine, cortisol, dehydroepiandrosterone and 
testosterone concentrations], Nihon Eiseigaku Zasshi. 64 (2009) 811-816. https://doi.org/10.1265/jjh.64.811.

[46] M.L. McHugh, Multiple comparison analysis testing in ANOVA, Biochem. Medica. 21 (2011) 203-209. https://doi.org/10.11613/bm.2011.029.

[47] N.E. Avis, S.L. Crawford, R. Green, Vasomotor symptoms across the menopause transition: Differences among women, Obstet. Gynecol. Clin. North Am. 45 (2018) 629-640. https://doi.org/10.1016/j.ogc.2018.07.005.

[48] A. Scalbert, G. Williamson, Dietary intake and bioavailability of polyphenols, J. Nutr. 130 (2000) 2073S-2085S. https://doi.org/10.1093/jn/130.8.2073s.

[49] W. Szeja, G. Grynkiewicz, A. Rusin, Isoflavones, their glycosides and glycoconjugates. Synthesis and biological activity, Curr. Org. Chem. 21 (2016) 218-235. https://doi.org/10.2174/1385272820666160928120822.

[50] Y.Z. Piao, J.B. Eun, Physicochemical characteristics and isoflavones content during manufacture of short-time fermented soybean product (cheonggukjang), J. Food Sci. Technol. 57 (2020) 2190-2197. https://doi.org/10.1007/s13197-020-04255-2.

[51] S. Kumari, S.K.C. Chang, Effect of cooking on isoflavones, phenolic acids, and antioxidant activity in sprouts of prosoy soybean (Glycine max), J. Food Sci. 81 (2016) C1679-C1691. https://doi.org/10.1111/1750-3841.13351.

[52] P. Dey, Gut microbiota in phytopharmacology: A comprehensive overview of concepts, reciprocal interactions, biotransformations and mode of actions, Pharmacol. Res. 147 (2019). https://doi.org/10.1016/j.phrs.2019.104367.

[53] J.K. Prasain, A. Arabshahi, D.R. Moore, G.A. Greendale, J.M. Wyss, S. Barnes, Simultaneous determination of 11 phytoestrogens in human serum using a 2 min liquid chromatography/tandem mass spectrometry method, J. Chromatogr. B Anal. Technol. Biomed. Life Sci. 878 (2010) 994-1002. https://doi.org/10.1016/j.jchromb.2010.02.032.

[54] T. Ahmed, S. Javed, A. Tariq, B. Budzyńska, G. D’Onofrio, M. Daglia, S.F. Nabavi, S.M. 
Nabavi, Daidzein and its effects on brain, Curr. Med. Chem. 24 (2017) 365-375. https://doi.org/10.2174/0929867323666161101140214.

[55] C.R. Cederroth, C. Zimmermann, S. Nef, Soy, phytoestrogens and their impact on reproductive health, Mol. Cell. $\quad$ Endocrinol. $355 \quad$ (2012) 192-200. https://doi.org/10.1016/j.mce.2011.05.049.

[56] D.M. Harris, E. Besselink, S.M. Henning, V.L.W. Go, D. Heber, Phytoestrogens induce differential estrogen receptor alpha- or beta-mediated responses in transfected breast cancer cells, Exp. Biol. Med. 230 (2005) 558-568. https://doi.org/10.1177/153537020523000807.

[57] N. Fuentes, P. Silveyra, Estrogen receptor signaling mechanisms, Adv. Protein Chem. Struct. Biol. 116 (2019) 135-170. https://doi.org/10.1016/bs.apcsb.2019.01.001.

[58] S. Qiu, C. Jiang, Soy and isoflavones consumption and breast cancer survival and recurrence: A systematic review and meta-analysis, Eur. J. Nutr. 58 (2019) 3079-3090. https://doi.org/10.1007/s00394-018-1853-4.

[59] H. Fritz, D. Seely, G. Flower, B. Skidmore, R. Fernandes, S. Vadeboncoeur, D. Kennedy, K. Cooley, R. Wong, S. Sagar, E. Sabri, D. Fergusson, Soy, red clover, and isoflavones and breast $\begin{array}{lllllll}\text { cancer: } & \text { A } & \text { systematic } & \text { review, } & \text { PLoS } & \text { One. } & \end{array}$ https://doi.org/10.1371/journal.pone.0081968.

[60] R. Girgert, G. Emons, C. Gründker, Estrogen signaling in ER $\alpha$-negative breast cancer: ER $\beta$

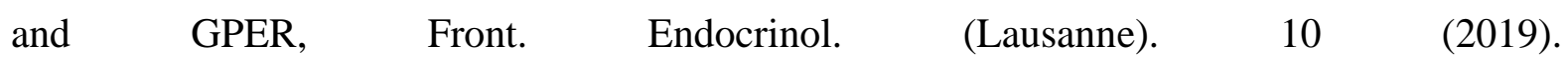
https://doi.org/10.3389/fendo.2018.00781.

[61] J.G. Meisler, V. Pinn, C. Kitt, L. LeResche, C. Stohler, J. Levine, Chronic pain conditions in women, J. Women's Heal. 8 (1999) 313-320. https://doi.org/10.1089/jwh.1999.8.313.

[62] R.C.A. Dias, J. Kulak Junior, E.H. Ferreira da Costa, R.M. Nisihara, Fibromyalgia, sleep disturbance and menopause: Is there a relationship? A literature review, Int. J. Rheum. Dis. 22 (2019) 1961-1971. https://doi.org/10.1111/1756-185X.13713.

[63] I.M.C.M. Rietjens, J. Louisse, K. Beekmann, The potential health effects of dietary 
phytoestrogens, Br. J. Pharmacol. 174 (2017) 1263-1280. https://doi.org/10.1111/bph.13622.

[64] J. Wei, J.R. Chen, E.M.A. Pais, T.Y. Wang, L. Miao, L. Li, L.Y. Li, F. Qiu, L.M. Hu, X.M. Gao, G.W. Fan, Oxyresveratrol is a phytoestrogen exerting anti-inflammatory effects through NF- $\kappa \mathrm{B}$ and estrogen receptor signaling, Inflammation. 40 (2017) 1285-1296. https://doi.org/10.1007/s10753-017-0572-y.

[65] Y. Sakamoto, J. Kanatsu, M. Toh, A. Naka, K. Kondo, K. Iida, The dietary isoflavone daidzein reduces expression of pro-inflammatory genes through PPAR $\alpha / \gamma$ and JNK pathways in adipocyte and macrophage co-cultures, PLoS One. $11 \quad$ (2016). https://doi.org/10.1371/journal.pone.0149676.

[66] H.Y. Li, L. Pan, Y.S. Ke, E. Batnasan, X.Q. Jin, Z.Y. Liu, X.Q. Ba, Daidzein suppresses proinflammatory chemokine $\mathrm{Cxcl} 2$ transcription in TNF- $\alpha$-stimulated murine lung epithelial cells via depressing PARP-1 activity, Acta Pharmacol. Sin. 35 (2014) 496-503. https://doi.org/10.1038/aps.2013.191.

[67] D. Giustarini, I. Dalle-Donne, D. Tsikas, R. Rossi, Oxidative stress and human diseases: Origin, link, measurement, mechanisms, and biomarkers, Crit. Rev. Clin. Lab. Sci. 46 (2009) 241-281. https://doi.org/10.3109/10408360903142326.

[68] K. Grintzalis, I. Papapostolou, D. Zisimopoulos, I. Stamatiou, C.D. Georgiou, Multiparametric protocol for the determination of thiol redox state in living matter, Free Radic. Biol. Med. 74 (2014) 85-98. https://doi.org/10.1016/j.freeradbiomed.2014.06.024. 
Fig. 1

A

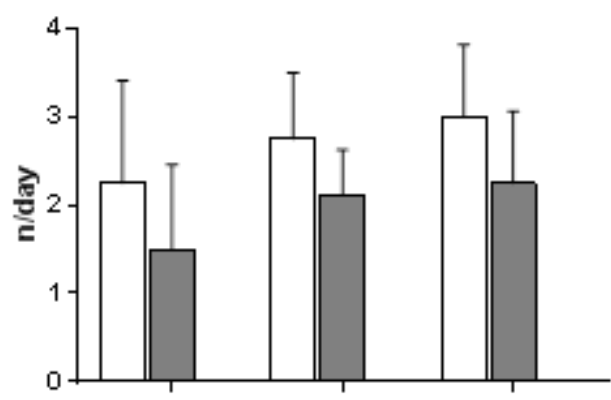

C

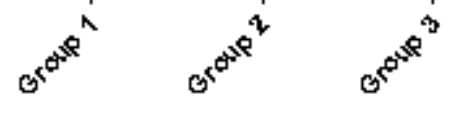

sexual desire decrease

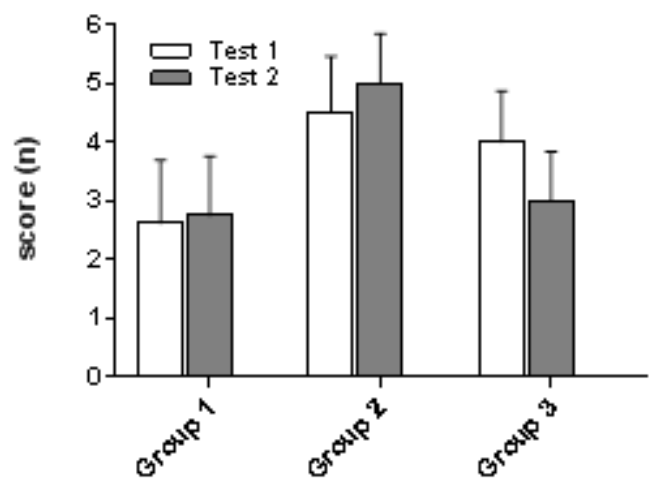

B flushes intensity

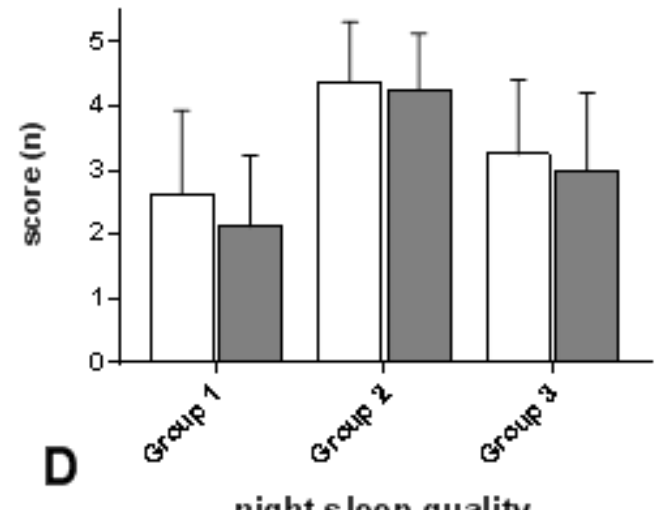

night s leep quality

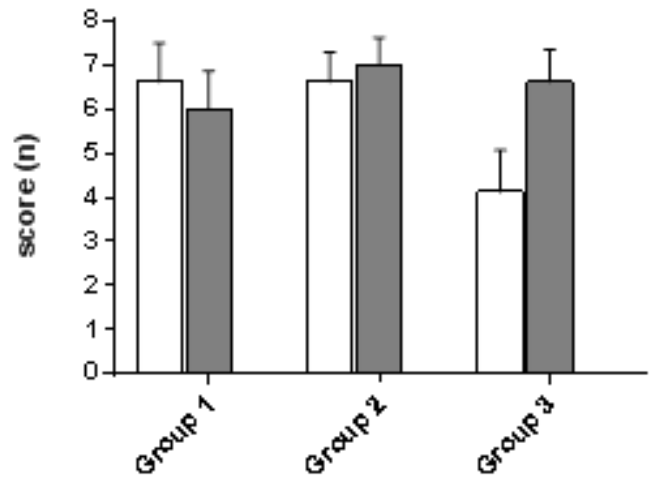


Fig. 2

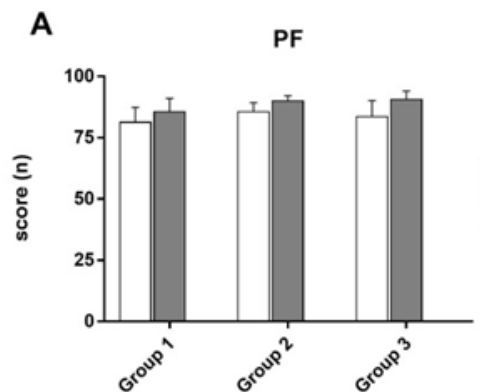

B RP

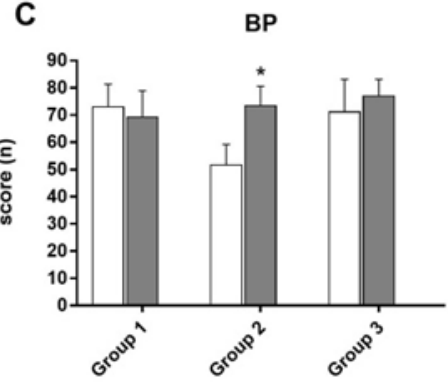

D GH

E

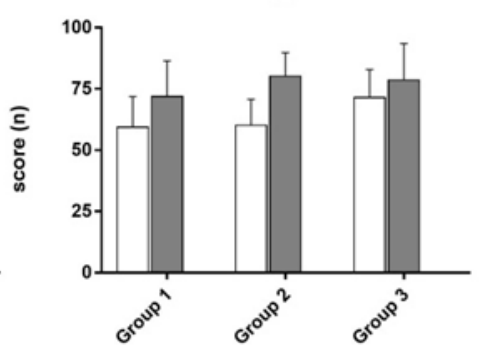

C

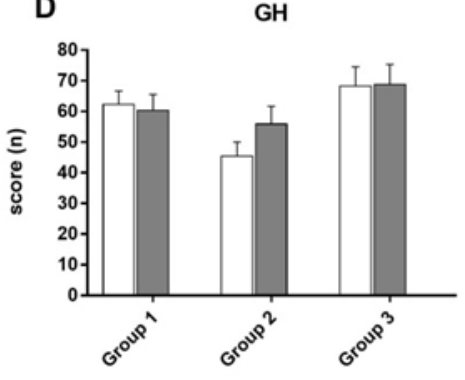

v

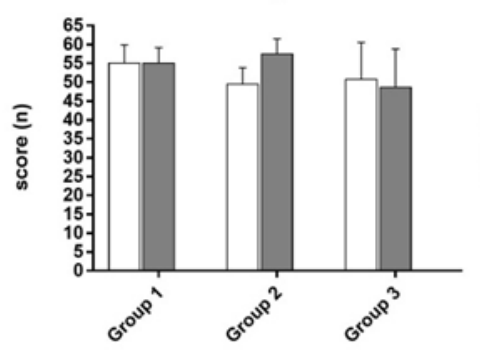

F
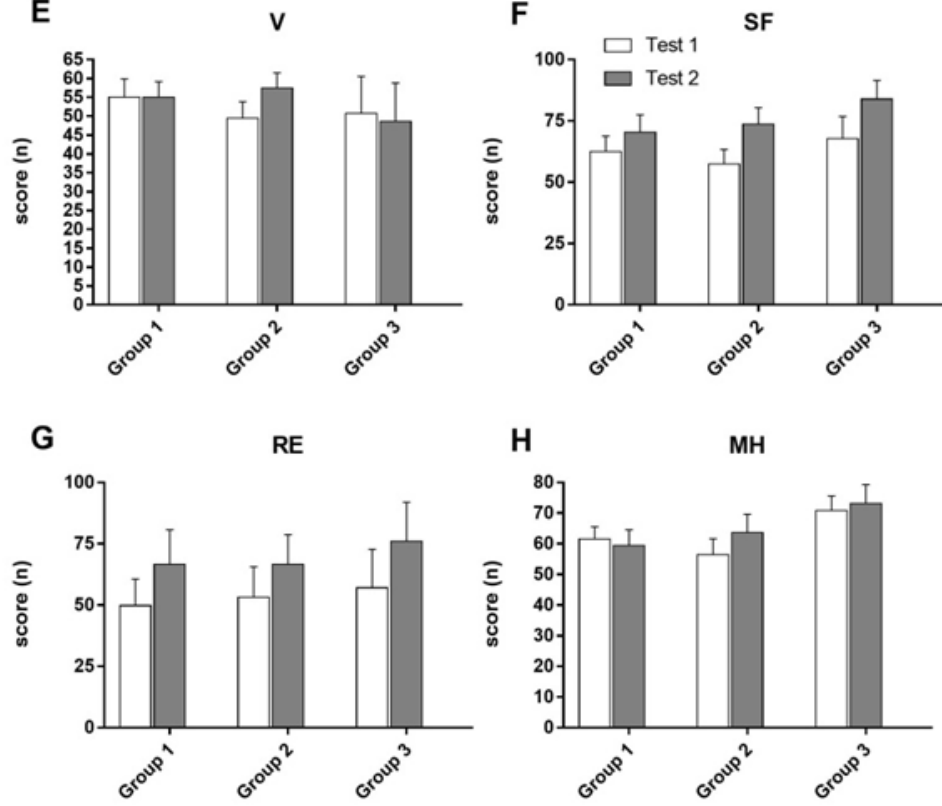
Fig. 3

A

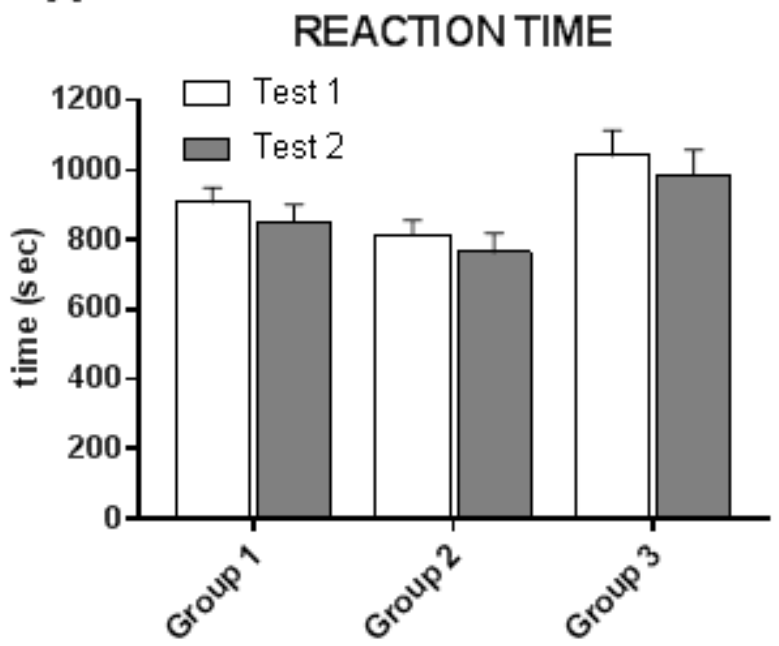

B

CORRECT ANSWERS

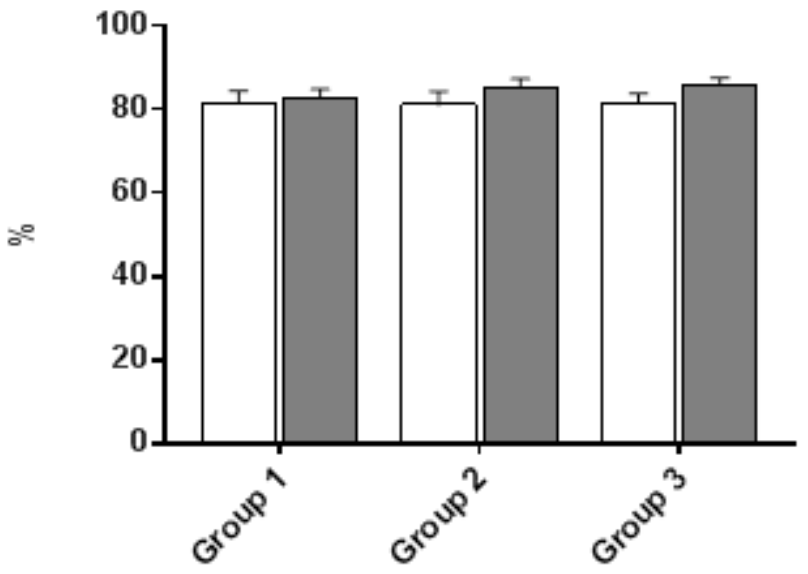


Fig. 4

\section{A}

DAIDZEIN

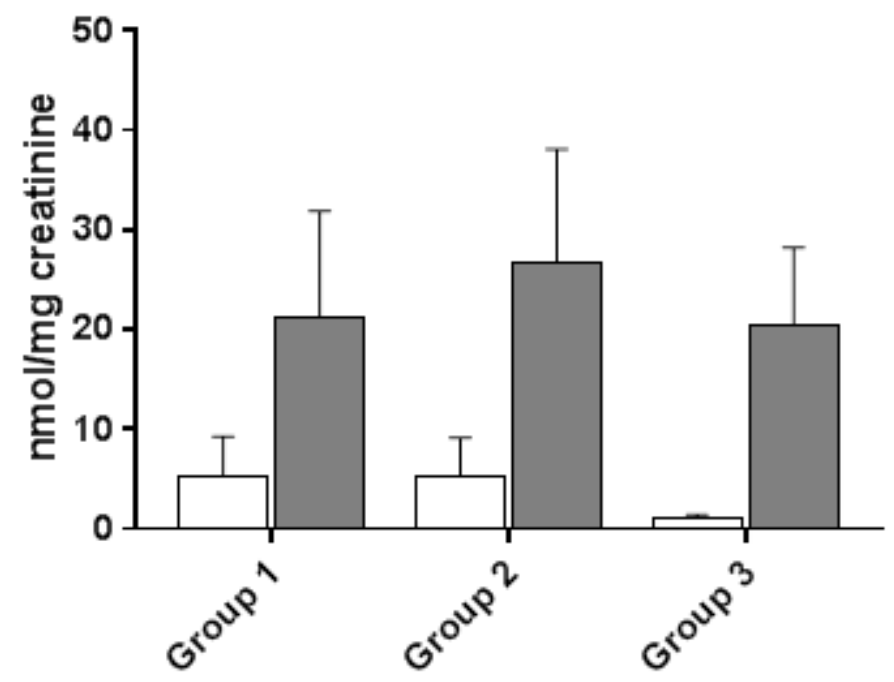

\section{B GENISTEIN}

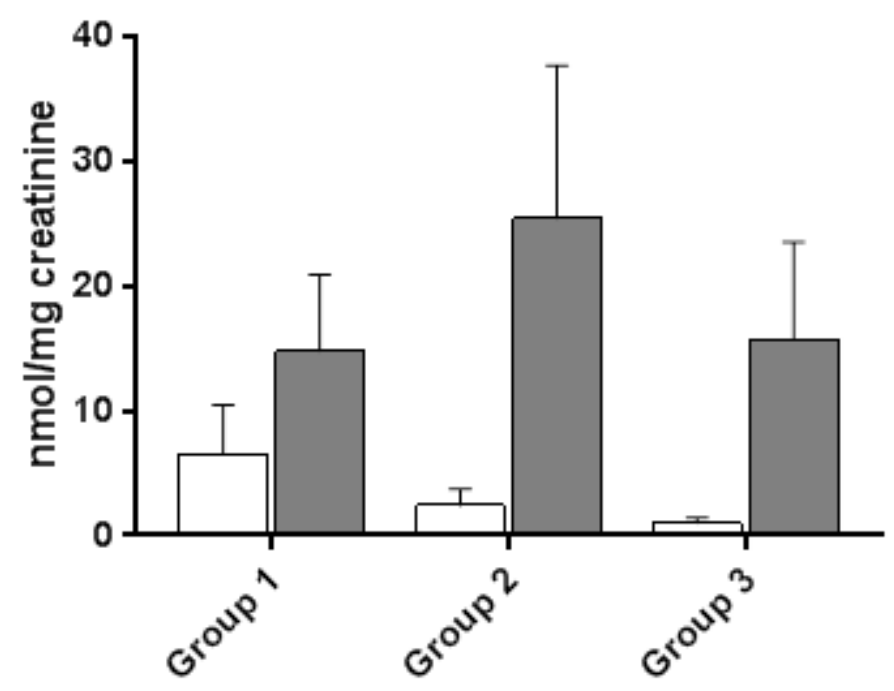

